\title{
Analisis Desain Map Rekam Medis
}

\section{Analysis of Medical Record Folder Design}

\author{
Heri Hernawan ${ }^{1}$ \\ Kori Puspita Ningsih ${ }^{2}$
}

\author{
1,2)Prodi Rekam Medis dan Informasi Kesehatan \\ Universitas Jenderal Achmad Yani Yogyakarta
}

Dengan alamat Jl. Brawijaya, Ringroad Barat, Ambarketawang, Gamping, Sleman

E-mail: herihernawan.unjani@gmail.com ${ }^{1}$,puspitakori@gmail.com ${ }^{2}$

\begin{abstract}
The medical record folder is a cover used for medical record forms in it to not scattered. The RMIK Lab of Jenderal Achmad Yani University Yogyakarta uses a medical record folder for student lab skills. The medical record map was designed in 2013 and has never been evaluated. This study aims to see the medical record folder 's function and analyze the medical record design folder from the physical, anatomical, and content aspects. This research uses descriptive research with a case study approach. The research location is in the Laboratory of Medical Records and Health Information (D-3), Faculty of Health, Jenderal Achmad Yani University, Yogyakarta. The results showed that the medical record folder in the RMIK Lab of Jenderal Achmad Yani University Yogyakarta was used to store and protect medical record forms, which are useful materials for students of the Medical Records and Health Information Study Program (D-3). The results of the analysis of the medical record folder on the physical, anatomical, and content aspects indicate that it is necessary to redesign the medical record folder on the anatomical elements, including: (1) adjusting the logo of the General Achmad Yani University Yogyakarta, (2) the identity of the hospital to become Unjani Yogya Hospital, (3) eliminating registration numbers and (4) adding a vital note column to attach color stickers to identify infectious diseases or write allergies on the medical record folder.
\end{abstract}

Keywords: analysis; design; folder; medical record

\begin{abstract}
Abstrak
Map rekam medis (folder) merupakan sampul yang digunakan untuk melindungi formulir-formulir rekam medis yang ada di dalamnya agar tidak tercecer. Lab RMIK Universitas Jenderal Achmad Yani Yogyakarta menggunakan map rekam medis untuk praktikum lab mahasiswa. Map rekam medis di desain pada tahun 2013 dan belum pernah dilakukan evaluasi. Penelitian ini bertujuan untuk mengetahui fungsi map rekam medis dan menganalisis desain map rekam medis dari aspek fisik, anatomi dan isi. Penelitian ini menggunakan penelitian deskriptif, dengan pendekatan studi kasus. Lokasi penelitian ini di Laboratorium Rekam Medis dan Informasi Kesehatan (D-3) Fakultas Kesehatan Universitas Jenderal Achmad Yani Yogyakarta. Hasil penelitian menunjukkan map rekam medis di Lab RMIK Universitas Jenderal Achmad Yani Yogyakarta digunakan untuk menyimpan dan melindungi formulir-formulir rekam medis yang merupakan bahan praktik mahasiswa Program Studi Rekam Medis dan Informasi Kesehatan (D-3). Hasil analisis map rekam medis pada aspek fisik, anatomi dan isi menunjukkan perlu dilakukan redesain map rekam medis pada aspek anatomi meliputi: (1) menyesuaikan logo Universitas Jenderal Achmad Yani Yogyakarta, (2) identitas rumah sakit menjadi Rumah Sakit Unjani Yogya, (3) menghilangkan
\end{abstract}


nomor registrasi dan (4) menambahkan kolom catatan penting untuk menempelkan stiker warna untuk mengidentifikasi penyakit menular maupun menuliskan alergi pada map rekam medis.

Kata kunci: analisis; desain;map; rekam medis

\section{Pendahuluan}

Rekam medis merupakan berkas yang berisi catatan dan dokumen tentang identitas pasien, pemeriksaan, pengobatan, tindakan dan pelayaan lain kepada pasien (Peraturan Menteri Kesehatan RI Nomor 269/Menkes/Per/III/2008 tentang Rekam Medis, 2008). Rekam medis diperlukan oleh fasilitas pelayanan kesehatan untuk memberikan informasi yang diperoleh dari pencatatan dan pengolahan data pasien sehingga dapat digunakan manajemen untuk menetapkan kebijakan, pengambilan keputusan, serta evaluasi terhadap hal-hal yang berkaitan dengan pelayanan yang diberikan (Nissaa et al., 2014).

Map rekam medis (folder) adalah sampul yang digunakan untuk melindungi formulir-formulir rekam medis yang ada di dalamnya agar tidak tercecer (Sudra, 2013).

Berdasarkan pengambilan data awal diketahui bahwa lab RMIK Universitas Jenderal Achmad Yani Yogyakarta mengunakan map rekam medis untuk praktikum lab mahasiswa. Hal ini berdampak identitas map rekam medis tidak akurat (Abdelhak, M., Grostik, S. A., Jacob, 2016). Pada aspek isi belum terdapat tempat stiker warna untuk mengidentifikasi pasien dengan penyakit menular, alergi dan catatan penting yang mendukung assasmen awal pasien standar Sasaran Keselamatan Pasien (SKP) dan Manajemen Informasi Rekam Medis (MIRM) (KARS, 2018). Hal ini berdampak mahasiwa kurang mengikuti perkembangan IPTEK khususnya pada bahan kajian isi dan format rekam medis sesaui standar akreditasi RS.

Map rekam medis didesain pada tahun 2013 dan belum pernah dilakukan evaluasi. Oleh karena itu perlu dilakukan analisis desain formulir pada map rekam medis untuk mengetahui kualitas aspek desain rekam medis. Penelitian ini bertujuan untuk mengetahui fungsi map rekam medis dan menganalisis desain map rekam medis dari aspek fisik, anatomi dan isi.

\section{Metode}

Penelitian ini menggunakan penelitian deskriptif, dengan pendekatan yang digunakan adalah studi kasus yaitu meneliti suatu permasalahan melalui suatu kasus yang terdiri dari unit tunggal, dalam hal ini yaitu analisa desain map rekam medis. Subjek penelitian ini adalah Ketua Prodi RMIK (D-3), Kepala Laboratorium, dan staf laboratorium Prodi RMIK (D-3) Fakultas Kesehatan Universitas Jenderal Achmad Yani Yogyakarta. Informan triangulasi pada penelitian ini adalah praktisi senior rekam medis di RSUD Tipe B Kota Yogyakarta. Objek pada penelitian ini adalah map rekam medis. Lokasi penelitian ini di Laboratorium Rekam Medis dan Informasi Kesehatan (D3) Fakultas Kesehatan Universitas Jenderal Achmad Yani Yogyakarta. Penelitian dilaksanakan mulai bulan April sampai Agustus 2020.

Metode pengumpulan data yang digunakan pada penelitian ini melalui observasi dengan instrument penelitian pedoman observasi yang berupa checklist. Observasi dilakukan pada map rekam medis dengan menekankan pada analisis desain rekam medis di aspek fisik, anatomi dan isi. Peneliti juga melakukan wawancara menggunakan instrumen penelitian pedoman wawancara. Wawancara pada penelitian ini dilakukan dengan Ketua Prodi RMIK (D-3), Kepala Laboratorium, dan staf laboratorium. Pengolahan data pada 
penelitian ini diawali dengan editing, kemudian dilakukan klasifikasi dari hasil wawancara dan analsisi desain map rekam medis pada aspek fisik, anatomi dan isi, kemudian dilanjutkan dengan pengelompokkan data dan penyajian data dalam bentuk narasi.

\section{Hasil dan Pembahasan}

\section{a. Fungsi Map Rekam Medis}

Map rekam medis di Lab RMIK Universitas Jenderal Achmad Yani Yogyakarta digunakan untuk menyimpan dan melindungi formulir-formulir rekam medis yang merupakan bahan praktik mahasiswa Program Studi Rekam Medis dan Informasi Kesehatan (D-3). Hal ini sesuai dengan pernyataan informan berikut:

"Map rekam medis sebagai wadah atau tempat dari formulir rekam medis supaya tidak tercecer, itu yang pertama, yg kedua berkaitan dengan lab digunakan sebagai bahan pembelajaran praktik supaya mahasiswa mengetahui bentuk maupun jenis map rekam medis".

\section{Kepala Lab RMIK}

Map rekam medis digunakan untuk menyatukan seluruh lembar rekam medis pasien sehingga menjadi satu riwayat utuh, melindungi lembar-lembar rekam medis didalamnya agar tidak mudah rusak, robek, terlipat dan mempermudah penyimpanan, pencarian, dan pemindahan berkas rekam medis (Sudra, 2013), (Nissaa et al., 2014).

Map rekam medis tersebut digunakan sebagai bahan praktikum skill mahasiswa pada bahan kajian manajemen rekam medis, dan desain formulir rekam medis. Map rekam medis merupakan satu diantara bahan praktik yang diperlukan di laboratorium rekam medis (Surat Keputusan Menteri Kesehatan Republik Indonesia No. HK.03.05/IV/14354.1/2010 tanggal 31 Desember 2010 tentang Standar Laboratorium Pendidikan Tenaga Kesehatan, 2010).

\section{b. Analisis Map Rekam Medis}

Jenis Map rekam medis di Lab RMIK Universitas Jenderal Achmad Yani Yogyakarta yaitu snelhecter (gambar 2). Menurut (Rustiyanto, 2011) Snelhechter adalah map yang terbuat dari kertas tebal atau plastik yang di dalamnya terdapat alat penjepit formulir yang terbuat dari logam.

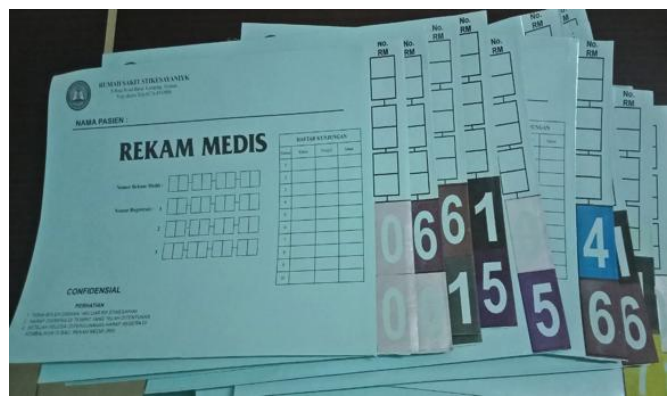

Gambar 1. Map rekam medis

Analisis map rekam medis dapat ditinjau dari aspek fisik, anotomi dan isi (Subinarto, 2018), (Nissaa et al., 2014). Berikut ini adalah aspek fisik, aspek anatomi, dan aspek isi map (folder) rekam medis yang saat ini digunakan di lab RMIK Universitas Jenderal Achmad Yani Yogyakarta adalah:

\section{1) Aspek Fisik}

Berikut hasil analisis map rekam medis pada aspek fisik (tabel 1):

Tabel 1. Aspek Fisik Map Rekam Medis

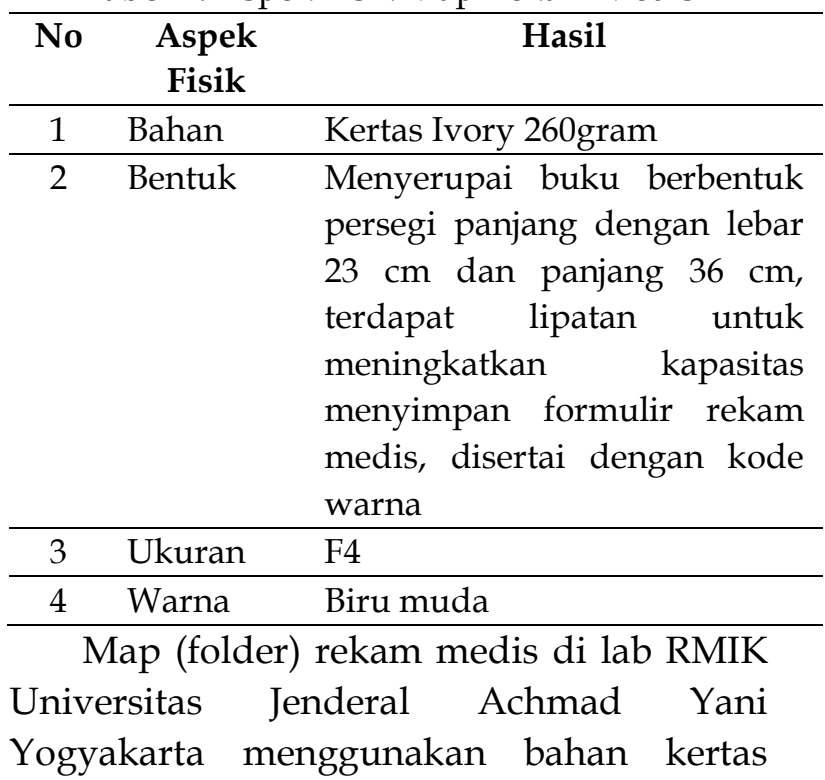


ivory 260gram. Map (folder) rekam medis tersebut berbahan tebal dan tidak mudah rusak dan sobek. Pada bagian permukaan kertas terlapis laminasi gloosy sehingga membuat warna tidak luntur dan tampak berkilauan. Hasil penelitian (Nissaa et al., 2014) menunjukkan untuk meredesain map rekam medis perlu menggunkaan bahan tebal dan tidak mudah sobek. Sedangkan menurut (Rustiyanto, 2011) bahan map rekam medis dapat berupa HVS, Art paper dan Matt paper, Art karton, duplex, ivory, samson kraft, dan BW/BC/manila.

Bentuk format map (folder) sebaiknya menggunakan ukuran yang sama dan standar (Abdelhak, 2016). Di lab RMIK Universitas Jenderal Achmad Yani Yogyakarta, bentuk map (folder) rekam medis menyerupai buku berbentuk persegi panjang lebar $23 \mathrm{~cm}$ dan panjang $36 \mathrm{~cm}$ dengan bentuk layout landscape untuk menyesuaikan dengan tempat peyimpanan. Terdapat lipatan untuk meningkatkan kapasitas menyimpan formulir rekam medis, disertai dengan kode warna untuk angka primer (2 digit terakhir). Dalam penjajaran dokumen rekam medis menggunakan kode warna untuk menghindari terjadinya misfile (Wati et al., 2011).

Ukuran dan jenis map (folder) hendaknya standar, atau disesuaikan dengan kebutuhan yang ada. Ukuran standar map yaitu F4 (Nissaa et al., 2014). Hal ini sesuai implementasi ukuran map RM di lab RMIK Universitas Jenderal Achmad Yani Yogyakarta.

Menurut (Abdelhak, 2016), Warna map (folder) harus cerah untuk menjaga nilai kontras antara warna map dengan tinta. Warna map rekam medis di lab RMIK Universitas Jenderal Achmad Yani Yogyakarta berwarna biru muda.

2) Aspek Anatomi

Berikut hasil analisis map rekam medis pada aspek anatomi (tabel 2):
Tabel 2. Aspek Anatomi Map Rekam Medis

\begin{tabular}{|c|c|c|}
\hline No & $\begin{array}{c}\text { Aspek } \\
\text { Anatomi } \\
\end{array}$ & Hasil \\
\hline 1 & Header & $\begin{array}{l}\text { Terdapat logo, nama, } \\
\text { alamat, dan nomor } \\
\text { telepon namun belum } \\
\text { update }\end{array}$ \\
\hline 2 & Introduction & $\begin{array}{l}\text { Terdapat judul map } \\
\text { "rekam medis" }\end{array}$ \\
\hline 3 & Intruction & $\begin{array}{l}\text { Terdapat informasi } \\
\text { confedensial dari map } \\
\text { rekam medis }\end{array}$ \\
\hline 4 & Body & $\begin{array}{l}\text { Terdapat Nama, } \\
\text { Nomor Rekam Medis, } \\
\text { Nomor Registrasi dan } \\
\text { Tahun kunjungan }\end{array}$ \\
\hline 5 & Font & $\begin{array}{l}\text { Font yang digunakan } \\
\text { menggunakan Times } \\
\text { New Roman untuk } \\
\text { identitas formulir } \\
\text { ukuran 14, judul } \\
\text { formulir ukuran 40, } \\
\text { identitas pasien dan } \\
\text { tahun kunjungan } \\
\text { ukuran 12. Sedangkan } \\
\text { font Arial ukuran } 14 \\
\text { digunakan } \\
\text { intruction. untuk }\end{array}$ \\
\hline 6 & Ruler & $\begin{array}{l}\text { Terdapat ruler pada } \\
\text { map rekam medis } \\
\text { untuk membatasi } \\
\text { heading dan body map }\end{array}$ \\
\hline 7 & Border & $\begin{array}{l}\text { Terdapat border dalam } \\
\text { map rekam medis }\end{array}$ \\
\hline
\end{tabular}

Pada bagian header map rekam medis menjelaskan identitas map rekam medis masih menggunakan nama "Rumah Sakit Stikes Ayani YK" dan logo Stikes Jenderal Achmad Yani. Pada identitas map rekam medis tersebut sebaiknya menggunakan identitas dan logo Universitas jenderal Achmad Yani Yogyakarta. Hal ini sesuai pernyataan informan berikut:

"ya, kita sudah melakukan penyesuaian menjadi Rumah Sakit Unjani Yogya, sesuai 
fungsinya sebagi model mini hospital di UKRM untuk praktik mahaiswa. Akan tetapi untuk map dan formulir belum dilakukan penyesuaian."

\section{Kepala lab RMIK}

Dengan belum adanya penyesuaian tersebut tentunya berdampak identitas map rekam medis tidak akurat (Abdelhak, 2016).

Terdapat introduction pada judul map "Rekam Medis" dan intruction yang berisi "Confidensial, Perhatian: (1) Tidak boleh dibawa/keluar dari Rumah Sakit Stikes Ayani YK; (2) Harap disimpan di tempat yang telah ditentukan; (3) Setelah selesai dipergunakan harap segera dikembalikan di Bagian Rekam Medis (RM)". Informasi pada intriduction dan istruction tersebut digunakan untuk menjelaskan tujuan dari formulir (Rustiyanto, 2011).

Pada body map rekam medis terdapat Nama, Nomor Rekam Medis, Nomor Registrasi dan Tahun kunjungan. Untuk nomor registrasi hanya terdapat 3 kolom, hal ini kurang tepat, karena nomor regitrasi diisi setiap pasien mendaftar. Apabila pasien mendaftar lebih dari 3 kali maka tidak dapat didikumentasikan di kolom regiarasi pada map rekam medis. Hal tersebut senada dengan penelitian (Astutik \& Endra, 2018) yang menyampaikan bahwa pasien yang telah terdaftar selanjutnya akan menerima nomor registrasi pasien. Nomor regitrasi bukan merupakan suatu komponen penting pada identifikasi pasien, sehingga tidak perlu dicantumkan dalam map rekam medis. Identifikasi pasien minimal 2 dari 3 komponen yaitu Nama, Nomor rekam medis, tanggal lahir (KARS, 2018).

Font yang digunakan pada map rekam medis terdiri dari 2 variasi menggunakan Times New Roman untuk identitas formulir ukuran 14, judul formulir ukuran 40, identitas pasien dan tahun kunjungan ukuran 12 serta font Arial ukuran 14 digunakan untuk intruction. Menurut (Rustiyanto, 2011), font menjelaskan terkait jenis huruf karena akan berpengaruh terhadap keterbacaan, sehingga harus diperhatikan ukuran, penebalan hruf, huruf miring, dan lain sebagainya.

Terdapat ruler untuk membatasi heading dan body map dan border pada map rekam medis. Rules terdapat garis vertical dan horizontal yang berguna untuk membagi form ke dalam bagian-bagian dan mengarahkan entry lokasi (Rustiyanto, 2011). Ruler dibuat langsung tanpa menggunakan garis putus-putus sehingga lebih jelas dan merupakan penekanan pada setiap item (Nissaa et al., 2014).

3) Aspek Isi

Berikut hasil analisis map rekam medis pada aspek isi (tabel 3):

Tabel 3. Aspek Isi Map Rekam Medis

\begin{tabular}{|c|c|c|}
\hline No & Aspek Isi & Hasil \\
\hline 1 & $\begin{array}{l}\text { Identitas } \\
\text { sarana } \\
\text { pelayanan } \\
\text { kesehatan }\end{array}$ & $\begin{array}{l}\text { Sudah tersedia identitas } \\
\text { nama sarana pelayanan } \\
\text { kesehatan, pada bagian } \\
\text { heading nama belum } \\
\text { update }\end{array}$ \\
\hline 2 & $\begin{array}{l}\text { Tulisan } \\
\text { "Confidensial" }\end{array}$ & $\begin{array}{ll}\text { Belum terdapat } & \text { tulisan } \\
\text { "Confidensial" } & \text { pada } \\
\text { sampul depan map } \\
\text { rekam medis }\end{array}$ \\
\hline 3 & Nama pasien & $\begin{array}{l}\text { Terdapat nama pasien } \\
\text { pada sampul depan map } \\
\text { rekam medis }\end{array}$ \\
\hline 4 & $\begin{array}{l}\text { Nomor } \\
\text { rekam medis }\end{array}$ & $\begin{array}{l}\text { Sudah tersedia } 8 \text { kolom } \\
\text { untuk pengisian nomor } \\
\text { rekam medis }\end{array}$ \\
\hline 5 & $\begin{array}{l}\text { Tahun } \\
\text { kunjungan } \\
\text { terakhir }\end{array}$ & $\begin{array}{l}\text { Tersedia } 10 \text { baris pada } \\
\text { tahun kunjungan } \\
\text { terakhir pada map } \\
\text { rekam medis }\end{array}$ \\
\hline
\end{tabular}

Pada aspek isi menjelaskan kelengkapan item pada map rekam medis (Nissaa et al., 2014). Map rekam medis minimal memuat informasi: (1) Identitas sarana pelayanan kesehatan ; (2) Tulisan "Confidential" atau "Rahasia" atau keduanya; (3) Nama pasien; (4) Nomor 
rekam medis; (5) Tahun kunjungan terakhir. Komponen tersebut sudah terdapat pada map rekam medis di lab RMIK Universitas Jenderal Achmad Yani Yogyakarta. Akan tetapi perlu diperhatikan dokumentasi pada rekam medis untuk mengidentifikasi pasien dengan penyakit menular, alergi dan sebagainya yang mendukung assasmen awal pasien pada pemenuhan standar Sasaran Keselamatan Pasien (SKP) dan Manajemen Informasi Rekam Medis (MIRM) (KARS, 2018). Oleh karena itu penting pada map rekam medis diberi diberikan tempat untuk menempelkan stiker warna, maupun menuliskan alergi pasien pada map rekam medis. Hal ini tentunya akan mendukug capaian pembelajaran Prodi RMIK (D-3) Fakultas Kesehatan Universitas Jenderal Achmad Yani Yogyakarta yaitu mampu mengikuti perkembangan IPTEK di bidang rekam medis untuk menghadapi persaingan global (P04) (Surat Keputusan Nomor: Skep 054/FKES/VIII/ 2019 tentang Kurikulum Pendidikan Program Studi Perekam dan Infokes (D-3) Fakultas Kesehatan Universitas Jenderal Achmad Yani Yogyakarta, 2019).

\section{Simpulan dan Saran}

Map rekam medis di Lab RMIK Universitas Jenderal Achmad Yani Yogyakarta digunakan untuk menyimpan dan melindungi formulir-formulir rekam medis yang merupakan bahan praktik mahasiswa Program Studi Rekam Medis dan Informasi Kesehatan (D-3). Setelah dilakukan analisis pada aspek fisik, anatomi dan isi dapat disimpulkan bahwa perlu dilakukan redesain map rekam medis pada aspek anatomi dengan menyesuaikan logo Universitas Jenderal Achmad Yani Yogyakarta, identitas rumah sakit menjadi Rumah Sakit Unjani Yogya, menghilangkan nomor registrasi dan menambahkan kolom catatan penting untuk menempelkan stiker warna untuk mengidentifikasi penyakit menular maupun menuliskan alergi pada map rekam medis.

\section{Ucapan Terima Kasih}

Terima kasih disampaikan kepada Universitas Jenderal Achmad Yani Yogyakarta yang telah mendanai keberlangsungan penelitian ini.

\section{Daftar Pustaka}

Abdelhak, M. (2016). Health Information: Management of a Strategic Resource. Saunders Elsevier.

Astutik, A., \& Endra, S. (2018). Rancang Bangun Aplikasi Rekam Medis Pasien Berbasis Web Pada Klinik TS Beauty Center Bojonegoro. Jsika, 7(1), 1-7.

KARS. (2018). Standar Nasional Akreditasi Rumah Sakit Edisi 1 (1st ed., pp. 1-421). KARS.

https://doi.org/10.15713/ins.mmj.3

Peraturan Menteri Kesehatan RI Nomor 269/Menkes/Per/III/2008 tentang Rekam Medis, (2008).

Surat Keputusan Menteri Kesehatan Republik Indonesia No. HK.03.05/IV/14354.1/2010 tanggal 31 Desember 2010 tentang Standar Laboratorium Pendidikan Tenaga Kesehatan, (2010).

Nissaa, K., Lestar, T., \& Mulyono, S. (2014). Pengembangan Desain Map Rekam Medis (Folder) dengan Kode Warna Di RSUD Pandan Arang Boyolali. 2, 158.

$$
\begin{array}{lrr}
\text { Surat } & \text { Keputusan Nomor: } & \text { Skep } \\
\text { 054/FKES/VIII/ } 2019 & \text { tentang } \\
\text { Kurikulum Pendidikan Program Studi } & \\
\text { Perekam dan Infokes (D-3) } & \text { Fakultas } \\
\text { Kesehatan Universitas } & \text { Jenderal } \\
\text { Achmad Yani Yogyakarta, (2019). }
\end{array}
$$

Rustiyanto, E. (2011). Manajemen Filing 
Dokumen Rekam Medis dan Informasi

Kesehatan. Politeknik Kesehatan Permata Indonesia.

Subinarto. (2018). Analisis Desain Formulir Ringkasan Masuk dan Keluar Rawat Inap Poltekkes Kemenkes Semaran , 2 ) RS Palang Biru Kutoarjo. Jurnal Rekam Medis Dan Informasi Kesehatan, 1(2), 76-81. https://doi.org/http://dx.doi.org/10. 31983jrmik.vli2.3850

Sudra, R. I. (2013). Rekam Medis. Universitas
Terbuka.

Wati, O. M., Pujihastuti, A., \& Riyoko. (2011). Tinjauan Pelaksanaan Penyimpanan dan Penjajaran Dokumen Rekam Medis di Ruang Filling RSUD Dr Moewardi. Jurnal Kesehatan, V(2), 20-28. 